\title{
Hydatid cyst submandibular gland, an unusal presentation: A case report
}

\author{
S Manandhar ${ }^{1}$, S Dhakal ${ }^{2}$, ST Chettri ${ }^{1}$ \\ Department of ORL and HNS ${ }^{1}$, Department of Pathology ${ }^{2}$
}

\begin{abstract}
This is a case report of a sixteen years old female presented in the Otolaryngology and Head \& Neck Surgery with left submandibular region which did not recovered by medical treatment. She underwent excision of left submandibular gland and hispathological examination confirmed the diagnosis as hydatid cyst of left submandibular gland.
\end{abstract}

Key words: Hydatid cyst, neck mass, submandibular gland.

\section{Introduction}

Hydatid disease is a zoonotic disease caused

by of tapeworm echinnococcus. Echinnococcus is a tissue infection human caused by larval stage of human caused by larval stage of echinnococcus granulosum and echinococcus multiocularis. Hydatid cyst is very uncommon in head and neck region especially in submandibular gland is rare and interesting ${ }^{1}$.

\section{Objective}

To make clinicians aware that hydatid cyst of submandibular gland should be kept in differential diagnosis in cases of unusal

\section{Address for correspondence}

Dr. Sriti Manandhar

Assistant Professor

Otolaryngology and Head and Neck Surgery

B.P. Koirala Institute of Health Sciences, Dharan

E-mail: sriticha@gmail.com

Mobile: 977-98413028 presentation of submandibular gland swelling.

\section{Case Summary}

A sixteen year old girl from Sunsari presented in ORL and Head and Neck Surgery with painful swelling in left submandibular region and had undergone incision and drainage with diagnosis of left suppurative submandibular lymphadenitis. On her first visit she had painful swelling in the submandibular region and had undergone incision and drainage. She stayed in hospital with 5 days course of intravenous antibiotics. Pus culture was sterile.

Though the pain had reduced but the swelling persisted. As the swelling did not subside she came for follow up. On examination, there was a small healed scar mark of $1.5 \mathrm{~cm}$ in the left submandibular region (Fig 1). 